\title{
Anthropometric variables as predictors of aspects of quality of life in persons with central obesity
}

\author{
Shirley Telles*, Niranjan Kala, Sachin Kumar Sharma and Acharya Balkrishna
}

\begin{abstract}
Objective: Central obesity has been shown to negatively influence the quality of life in centrally obese persons of both sexes. In a population of 740 centrally obese Asian-Indian adults, the present study was conducted to determine whether body mass index (BMI), waist circumference, hip circumference (HC), waist-hip ratio (WHR) and sagittal abdominal diameter (SAD) could predict different domains of quality of life. The differences based on gender and age were also determined. Linear regression analyses were carried out and the level of statistical significance (a) was set at 0.05 .

Results: Body mass index, HC, WHR and SAD were significant predictors for different domains of quality of life as well as for the summated total quality of life. BMI was found to be the most important predictor among all predictors across age groups and both sexes.
\end{abstract}

Keywords: Central obesity, Anthropometry, Indian adults, Quality of life

\section{Introduction}

Asian Indians show relatively greater accumulation of visceral fat and susceptibility to central obesity and this has been termed as the "Asian Indian phenotype" [1, 2]. An ongoing ICMR-INDIAB study surveyed 16,000 individuals aged 20 years and above from urban as well as rural areas of India [3]. The first phase of the study reported a higher prevalence of isolated central obesity compared to generalized obesity independent of ethnicity. Central obesity is worrisome considering its association with an increased risk of endothelial dysfunction, diabetes mellitus, cardiovascular disease, inflammation, insulin resistance, metabolic syndrome, hypercholesterolemia, and certain cancers [4].

Apart from the risks of developing specific disorders, central obesity has been shown to negatively influence other aspects of life. In 56 overweight and obese Brazilian women with a short stature who had central obesity there was a tendency towards low self-esteem and a negative

\footnotetext{
*Correspondence: shirleytelles@gmail.com
}

Patanjali Research Foundation, Patanjali Yogpeeth, Haridwar, Uttarakhand 249405, India body image [5]. In another study on 246 Iranian soldiers, an inverse association was reported between self-esteem and central obesity [6]. Central obesity also influenced work ability in 11,637 Finnish persons who showed an association between the waist-hip ratio (WHR) and low work ability index [7]. In males especially, abdominal obesity has been associated with lower testosterone levels and libido $[8,9]$. Some of these effects are due to chemicals secreted by the adipose tissue deposited intra-peritoneally, while other effects are more a product of social and psychological factors which can influence the mood.

The present cross-sectional study aimed at (i) determining whether the body mass index, waist circumference, hip circumference, waist-hip ratio and sagittal abdominal diameter could predict the quality of life in 740 persons with central obesity and (ii) to determine differences based on gender and age.

\section{Main text \\ Methods \\ Study design and recruitment of research participants}

The study was a cross sectional trial. Seven hundred and forty centrally obese persons of both sexes were 
recruited from four regions of India (419 females; group mean age $\pm S D, 44.9 \pm 10.5$ years). The participants were from north (34.5\%), south (34.2\%), east (13.9\%) and west (17.4\%) regions of India based on a standard categorization of the regions [10]. The inclusion criteria were (i) presence of central obesity i.e., waist circumference $\geq 80 \mathrm{~cm}$ for women and $\geq 90 \mathrm{~cm}$ for men [11], (ii) not currently taking part in any weight loss program and (iii) willingness to take part in the study. The criteria for exclusion were (i) presence of diseases/conditions associated with obesity such as type 2 diabetes mellitus and cardiovascular disease and (ii) obesity secondary to hormonal imbalance, other medical conditions or medication such as steroids. Participants were recruited through advertisements in local newspapers and flyers with the help of social workers connected to the research institute conducting the research. The participants' signed informed consent was taken individually. Ethical approval from the Ethics Committee of Patanjali Research Foundation, Haridwar, India was obtained (Approval No. YRD-017/022).

\section{Assessments}

The assessments are mentioned below.

\section{Waist circumference (WC)}

Participants were lightly clothed and asked to stand upright with their weight evenly distributed on both feet. The tape measure (Gülick Anthropometric tape Model J00305, Lafayette Instrument, U.S.A.) was wrapped around the abdomen between the iliac crest and the inferior costal margin. The tape was kept parallel to the floor and the measurement was taken to the nearest $0.1 \mathrm{~cm}$ after a normal exhalation.

\section{Sagittal abdominal diameter (SAD)}

The participants were asked to lie supine on their back. A caliper was used with two sliding arms attached parallel to a vertical scale [Holtain-Kahn Abdominal Caliper $50 \mathrm{~cm}$ (98.609XL), U.K.] following the standard method for the use of the caliper [12]. The lower arm of the caliper was placed at the level of L4-L5 under the participant and the upper arm of the caliper was lowered without compressing the abdomen. The reading on the vertical scale after a normal exhalation was noted in $\mathrm{cm}$.

\section{Hip circumference $(H C)$}

The hip circumference was measured around the pelvis at the point of maximal protrusion of the buttocks in a horizontal plane.

\section{Body mass index (BMI)}

The body mass index (BMI) was calculated as the body weight (in $\mathrm{kg}$ ), divided by the height (in meters) squared.

\section{Waist-hip ratio (WHR)}

The ratio of the waist circumference to the hip circumference was derived as WC (in centimeters) divided by $\mathrm{HC}$ (in centimeters) or the waist-hip ratio (WHR).

\section{Quality of life (QoL)}

The quality of life was assessed using MooreheadArdelt quality of life (QoL) Questionnaire which consists of six items that assess six different aspects of quality of life viz., general self-esteem, physical activity, social contacts, satisfaction concerning work, pleasure related to sexuality, and focus on eating behavior [13]. The scores range from -0.5 to 0.5 . The sum of these 6 scores provides an overall QoL score. Each score is classified into five categories (very poor: -3.0 to -2.1 ; poor: -2.0 to -1.1 ; fair: -1.0 to 1.0 ; good: 1.1 to 2.0 : and very good: 2.1 to 3.0 ).

\section{Data analysis}

Data were analyzed using SPSS (Version 24.0).

Separate linear regression analyses were carried out to determine if the five anthropometric variables (i.e., BMI, WC, HC, WHR, and SAD) would predict six domains of quality of life as well as total quality of life based on anthropometric measures, in a regression analysis model. The data were divided gender-wise (as 321 males and 419 females) and age-wise as three age groups i.e., $18-30$ years, $31-50$ years and $51-70$ years. It has been reported that age affects various aspects of quality of life differently in overweight and obese persons [14]. For example those aspects of quality of life which involve physical functions deteriorate with increasing age in overweight and obese persons whereas self-esteem and public distress improve with age. Hence in the present study age wise categorization was done. Separate linear regression analyses were further carried out on these groups to see the age and gender specific variations in the results.

\section{Results}

Results of the of linear regression analyses for the whole group, both genders and three age groups are given in Table 1.

\section{Regression analyses for the whole group $(n=740)$}

In the whole group, BMI acted as a significant negative predictor for total quality of life (beta 
Table 1 Results of linear regression analyses for the whole group, both genders and three age groups

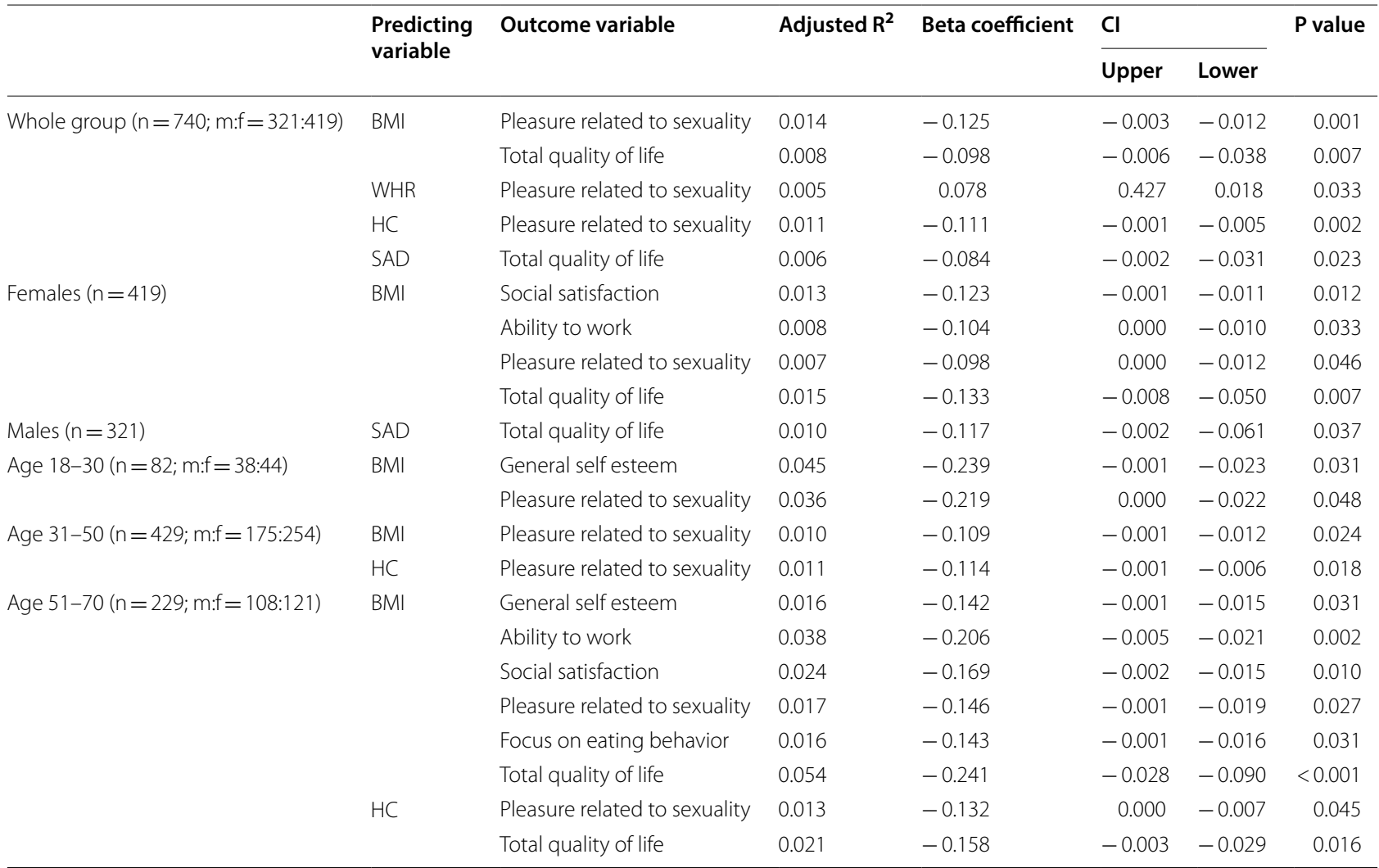

$C I$ confidence interval, BMI: body mass index, $H C$ hip circumference, m:f male:female ratio, $S A D$ sagittal abdominal diameter, WHR waist hip ratio

coefficient $=-0.098, \quad \mathrm{P}=0.007)$ and for pleasure related to sexuality (beta coefficient $=-0.125$, $\mathrm{P}=0.001)$. WHR positively predicted pleasure related to sexuality (beta coefficient $=0.078, \quad \mathrm{P}=0.033$ ), $\mathrm{HC}$ negatively predicted pleasure related to sexuality (beta coefficient $=-0.111, \mathrm{P}=0.002$ ) and SAD negatively predicted total quality of life (beta coefficient $=-0.184, \mathrm{P}=0.023$ ) in this group.

\section{Regression analysis gender-wise}

Regression analyses for females $(n=419) \quad$ BMI was found to be a significant negative predictor for social satisfaction (beta coefficient $=-0.123, \mathrm{P}=0.012$ ), ability to work (beta coefficient $=-0.104, \mathrm{P}=0.033$ ), pleasure related to sexuality (beta coefficient $=-0.198, \mathrm{P}=0.046$ ) and total quality of life (beta coefficient $=-0.133, \mathrm{P}=0.007$ ) in females.

Regression analyses for males $(n=321)$ SAD negatively predicted total quality of life (beta coefficient $=-0.117, \mathrm{P}=0.037$ ) in males.

\section{Regression analysis age-wise}

Regression analyses for age group 18-30 $(n=82)$ BMI negatively predicted general self esteem (beta coefficient $=-0.239, \mathrm{P}=0.031$ ) and pleasure related to sexuality (beta coefficient $=-0.219, \mathrm{P}=0.048$ ) in this age group.

Regression analyses for age group 31-50 $(n=429) \quad$ BMI negatively predicted pleasure related to sexuality (beta coefficient $=-0.109, \mathrm{P}=0.024$ ) and $\mathrm{HC}$ also negatively predicted pleasure related to sexuality (beta coefficient $=-0.114, \mathrm{P}=0.018$ ) in this age group.

Regression analyses for age group 51-70 $(n=70) \quad$ In this age group, BMI negatively predicted general self esteem (beta coefficient $=-0.142, \mathrm{P}=0.031$ ), ability to work (beta coefficient $=-0.206, \mathrm{P}=0.002$ ), social satisfaction (beta coefficient $=-0.169, \mathrm{P}=0.010$ ), pleasure related to sexuality (beta coefficient $=-0.146, \mathrm{P}=0.027$ ), focus on eating behavior (beta coefficient $=-0.143, \mathrm{P}=0.031$ ) and total quality of life (beta coefficient $=-0.241, \mathrm{P}<0.001$ ) significantly. $\mathrm{HC}$ negatively predicted pleasure related to sexuality (beta coefficient $=-0.132, \mathrm{P}=0.045$ ) and total 
quality of life (beta coefficient $=-0.158, \mathrm{P}=0.016$ ) in this age group.

\section{Discussion}

In 740 adult Indians with central obesity, several anthropometric measures predicted the quality of life. The BMI was the most important predictor of different aspects of quality of life, which was true across age groups and gender.

The total quality of life (QoL) was negatively predicted by three variables, BMI, SAD and HC. The BMI predicted the total QoL in the whole group, females and old persons (i.e., aged 51-70 years). The sagittal abdominal diameter (SAD) predicted total QoL in the whole group and in all males. The SAD is a better measure of visceral fat rather than subcutaneous fat [12]. Visceral fat contributes to chronic inflammation which is associated with various diseases including cancer [15]. The association between high SAD with poor QoL could be related to these negative effects on health.

The HC negatively predicted the total Qol in old persons. In a Swedish female cohort, larger hip circumference was associated with significantly fewer adverse health outcomes [16]. However this relation seems to be ethnicity dependent, since in an Asian-Chinese population larger hip circumference was associated with incident high triglycerides, low HDL-C, and multiple metabolic abnormalities [17]. In the absence of data on an Asian-Indian population, the data on Asian-Chinese persons may be considered of greater relevance to the present study, despite the considerable genetic diversity of Asian-Indians [18]. Hence the $\mathrm{HC}$ is also an independent predictor of health risks which could explain its relation with the total QoL.

The BMI acted as a negative predictor for general self esteem in persons of a young age group (i.e., 20-30 years) as well as in an old age group (i.e., 51-70 years). Irrespective of physical characteristics, self esteem is believed to have a trajectory across the course of life, increasing during young and middle adulthood, reaching a peak at about 60 years, and then declining in old age [19]. This could contribute to the negative association between BMI and self esteem in old age. In the younger age group, obesity is associated with psychosocial consequences such as perceived stress and social marginalization [20,21], which could contribute to the relation found between low self esteem and higher BMI.

The BMI was a negative predictor for satisfactory social contacts in females as well as in old persons. A direct association between BMI and depressive symptoms has been reported along with influencing the body image [22]. The association was gender dependent with a greater effect on females than in males. Mental depression along with poor body image can be responsible for unsatisfactory social contacts in females and old persons with a high BMI.

The ability to work was negatively predicted by the BMI in females and old persons. This could be explained by earlier studies reporting increased neuromuscular fatigue related to stress, a sedentary lifestyle and obesity in both men and women [23, 24]. Work ability was previously shown to be inversely related to the BMI in a Finnish population [7].

Pleasure related to sexuality was predicted by three variables, BMI, HC and WHR; with BMI being a significant negative predictor for all cohorts except males. $\mathrm{HC}$ was a negative predictor in the whole group, middle aged persons (i.e., 31-50 years) and old persons (i.e., 51-70 years), while WHR was a positive predictor in the whole group. Hip circumference was negatively correlated with sperm concentration in males [25]. Low testosterone levels and decreased libido were associated with obesity and metabolic syndrome $[8,9]$. Hence BMI and $\mathrm{HC}$ appear to predict impaired reproductive health, which could influence the aspect of quality of life related to sexuality. The reason why the waist-hip ratio could be positively related to sexual health is the negative relation with the $\mathrm{HC}$ (the denominator of the ratio).

The approach towards food in older persons (i.e., 51-70 years) was negatively predicted by the BMI in our study. The reason could be that older people with a high BMI are concerned about their health and food choices [26].

In summary in the population of centrally obese adult Asian Indians given the genetic predisposition to central obesity, anthropometric indices studied, viz. BMI, SAD, $\mathrm{HC}$ and WHR acted as significant predictors of quality of life, though the BMI was the best predictor across age groups and for both sexes.

\section{Limitations}

In the present cross-sectional study external validity may be compromised as the results may be applicable mainly to the population studied (i.e., Asian Indians with central obesity) but may not be generalizable to a wider population (for example, to all centrally obese populations world wide or to Asian Indians with overall obesity rather than central obesity alone) [27]. This is a limitation of the study.

\footnotetext{
Abbreviations

BMl: body mass index; $\mathrm{Cl}$ : confidence interval; HC: hip circumference; HDL-C: high density lipoprotein cholesterol; ICMR-INDIAB: Indian Council of Medical Research-India Diabetes; QoL: quality of life; SAD: sagittal abdominal diameter; SD: standard deviation; SPSS: Statistical Package for Social Sciences; WC: waist circumference; WHR: waist-hip ratio.
} 


\section{Authors' contributions}

ST conceptualized the experiment, interpreted the data and did the manuscript writing. NK analyzed the data, did the literature review, carried out statistics and helped to compile the manuscript. SKS helped to design the study, supervised data taking, analysis and helped to compile the manuscript. $A B$ conceptualized the study, finalized executing the study and provided funding and infrastructure. All authors read and approved the final manuscript.

\section{Acknowledgements}

The authors gratefully acknowledge the help of Dr. Jaideep Arya, the main Coordinator of Patanjali Yog Samiti, Haridwar, Uttarakhand, India. The participants who were recruited for the study are gratefully acknowledged for their co-operation.

\section{Competing interests}

The authors declare that they have no competing interests.

\section{Availability of data and materials}

The individual data are available in the archives of the laboratory and can be obtained from the corresponding author on request.

\section{Consent for publication}

Not applicable.

\section{Ethics approval and consent to participate}

The study had the ethical approval of the Ethics Committee of Patanjali Research Foundation, Haridwar, India (Approval No. YRD-017/022) and individual signed consent from each participant was taken.

\section{Funding}

The study was funded by Patanjali Research Foundation Trust.

\section{Publisher's Note}

Springer Nature remains neutral with regard to jurisdictional claims in published maps and institutional affiliations.

Received: 21 August 2018 Accepted: 20 September 2018 Published online: 25 September 2018

\section{References}

1. Joshi SR. Metabolic syndrome-emerging clusters of the Indian phenotype. J Assoc Physicians India. 2003;51:445-6.

2. Deepa R, Sandeep S, Mohan V. Abdominal obesity, visceral fat and type 2 diabetes-Asian Indian phenotype. In: Mohan V, Rao GHR, editors. Type 2 diabetes in South Asians: epidemiology, risk factors and prevention. New Delhi: Jaypee Brothers Medical Publishers (P) Ltd; 2006. p. 138-52.

3. Pradeepa R, Anjana RM, Joshi SR, Bhansali A, Deepa M, Joshi PP, et al. Prevalence of generalized \& abdominal obesity in urban \& rural Indiathe ICMR-INDIAB study (Phase-I) [ICMR-INDIAB-3]. Indian J Med Res. 2015:142(2):139-50

4. Carmienke S, Freitag MH, Pischon T, Schlattmann P, Fankhaenel T, Goebel $\mathrm{H}$, et al. General and abdominal obesity parameters and their combination in relation to mortality: a systematic review and meta regression analysis. Eur J Clin Nutr. 2013:67(6):573-85.

5. Bueno NB, Florêncio TT, Cavalcante FA, Lins IL, Clemente AG, Sawaya AL. Higher central fat and poor self-body image in short-stature overweight/ obese women living in Brazilian shantytowns. PeerJ. 2016;4:e2547.

6. Rahmani A, Varkaneh HK, Yekaninejad M, Dorostymotlagh AR. The relationship of general and abdominal obesity with self-esteem in Iranian soldier of Tehran barracks. JNSD. 2016; 2(5). http://jnsd.tums.ac.ir/index .php/jnsd/article/view/73.
7. Laitinen J, Näyhä S, Kujala V. Body mass index and weight change from adolescence into adulthood, waist-to-hip ratio and perceived work ability among young adults. Int J Obes (Lond). 2005;29(6):697-702.

8. Wang C, Jackson G, Jones TH, Matsumoto AM, Nehra A, Perelman MA, et al. Low testosterone associated with obesity and the metabolic syndrome contributes to sexual dysfunction and cardiovascular disease risk in men with type 2 diabetes. Diabetes Care. 2011;34(7):1669-75.

9. Low sex drive- caused by abdominal obesity. http://www.herballove .com/guide/low-sex-drive-caused-abdominal-obesity. Accessed 8 Aug 2018.

10. List of regions-zone-wise, division and state-wise. https://www.licindia. in/.../Empanelment-of-TPAs-for-providing-services-for-LIC. Accessed 8 Aug 2018.

11. International Diabetes Federation. The IDF consensus worldwide definition of the metabolic syndrome; 2006. https://www.idf.org/our-activities ladvocacy-awareness/resources-and-tools/60:idfconsensus-worldwidedefinitionof-the-metabolic-syndrome.html. Accessed 8 Aug 2018.

12. Sampaio LR, Simões EJ, Assis AM, Ramos LR. Validity and reliability of the sagittal abdominal diameter as a predictor of visceral abdominal fat. Arq Bras Endocrinol Metabol. 2007:51:980-6.

13. Myers JA, Clifford JC, Sarker S, Primeau M, Doninger GL, Shayani V. Quality of life after laparoscopic adjustable gastric banding using the Baros and Moorehead-Ardelt Quality of Life Questionnaire II. JSLS. 2006;10:414-20.

14. Zabelina DL, Erickson AL, Kolotkin RL, Crosby RD. The effect of age on weight-related quality of life in overweight and obese individuals. Obesity (Silver Spring). 2009;17(7):1410-3.

15. Hamdy O, Porramatikul S, Al-Ozairi E. Metabolic obesity: the paradox between visceral and subcutaneous fat. Curr Diabetes Rev. 2006:2:367-73.

16. Lissner L, Björkelund C, Heitmann BL, Seidell JC, Bengtsson C. Larger hip circumference independently predicts health and longevity in a Swedish female cohort. Obes Res. 2001;9(10):644-6.

17. Katz EG, Stevens J, Truesdale KP, Cai J, Adair LS, North KE. Hip circumference and incident metabolic risk factors in Chinese men and women: the People's Republic of China study. Metab Syndr Relat Disord. 2011;9(1):55-62.

18. Dolgin E. Indian ancestry revealed. In: Nature; 2009. https://www.natur e.com/news/2009/090922/full/news.2009.935.html. Accessed 8 Aug 2018

19. Orth U, Trzesniewski KH, Robins RW. Self-esteem development from young adulthood to old age: a cohort-sequential longitudinal study. J Pers Soc Psychol. 2010:98(4):645-58.

20. Smith MJ, Theeke L, Culp S, Clark K, Pinto S. Psychosocial variables and self-rated health in young adult obese women. Appl Nurs Res. 2014;27(1):67-71.

21. Strauss RS, Pollack HA. Social marginalization of overweight children. Arch Pediatr Adolesc Med. 2003:157(8):746-52.

22. Eidsdottir ST, Kristjansson AL, Sigfusdottir ID, Garber CE, Allegrante JP. Association between higher BMI and depressive symptoms in Icelandic adolescents: the mediational function of body image. Eur J Public Health 2014:24(6):888-92.

23. Mehta RK. Impacts of obesity and stress on neuromuscular fatigue development and associated heart rate variability. Int J Obes (Lond) 2015;39(2):208-13.

24. Jarosz PA, Davis JE, Yarandi HN, Farkas R, Feingold E, Shippings SH, et al. Obesity in urban women: associations with sleep and sleepiness, fatigue and activity. Womens Health Issues. 2014;24(4):e447-54.

25. Fejes I, Koloszár S, Szöllosi J, Závaczki Z, Pál A. Is semen quality affected by male body fat distribution? Andrologia. 2005;37(5):155-9.

26. Van-Meer F, Charbonnier L, Smeets P. Food decision-making: effects of weight status and age. Curr Diab Rep. 2016;16(9):84.

27. Model Assessment. https://www.reed.edu/economics/parker/s12/312/ notes/Notes7.pdf. Accessed 11 Sep 2018. 